\title{
Extent, patterns and demographic correlates for physical fighting among school-attending adolescents in Namibia: Examination of the 2013 Global School-based Health Survey
}

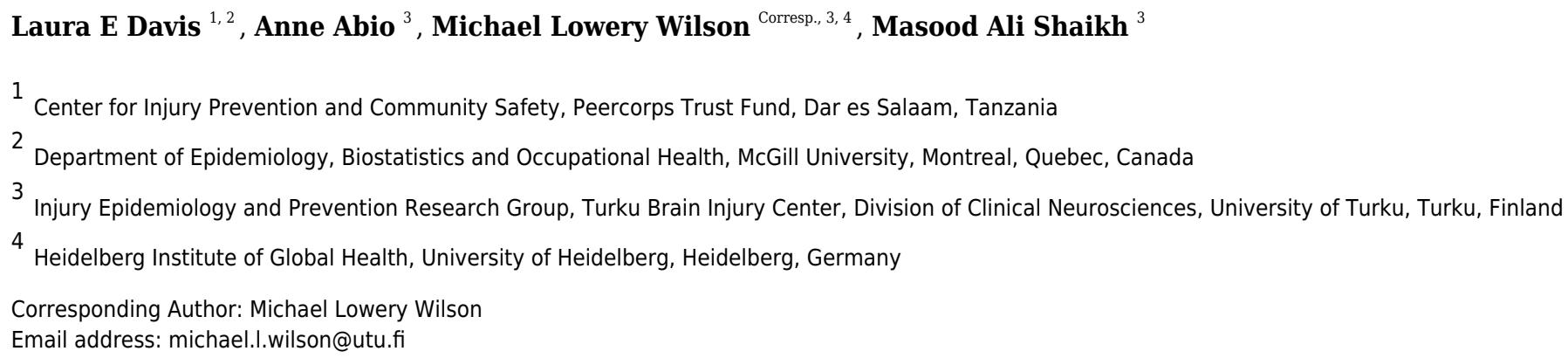

Background: Physical fighting is particularly detrimental for young people, often affecting other areas of their developing lives, such as relationships with friends and family and participating in risky behaviors. We aim to quantify the amount of problematic physical fighting in Namibian adolescents and identify modifiable risk factors for intervention. Methods: We used the Namibia 2013 Global School-based Student Health Survey (GSHS). This survey collects health-related information on school-attending adolescents in grades 7 to 12 . We defined physical fighting as having participated in at least two physical fights in the 12 months prior to responding to the survey. Factors that may be associated with physical fighting were identified a prior based on the literature and included age, sex, anxiety, suicide planning, truancy, physical activity, bullying victimization, presence of supportive parental figures, presence of helpful peers, extent of social network, and food insecurity. Multivariable logistic regression models were created to identify factors associated with physical fighting. Results: 4,510 adolescents were included in the study. $52.7 \%$ female. $16.9 \%$ of adolescents reported engaging in at least two physical fights in the previous year. Factors associated with an increased odds of physical fighting included having a suicide plan, anxiety, truancy, food deprivation and being bullied. Increased age and loneliness were associated with a decreased odds of physical fighting. Conclusion: This study identifies problematic physical fighting among adolescents in Namibia. We recommend public health and school-based programming that simultaneously targets risk behaviours and conflict resolution to reduce rates of physical fighting. 
1 Extent, patterns and demographic correlates for physical fighting among school-attending adolescents in Namibia: Examination of the 2013 Global School-based Health Survey

Laura E. Davis ${ }^{1,2}$, Anne $_{\text {Abio }^{3}}$, Michael Lowery Wilson ${ }^{3,4}$ Masood Ali Shaikh ${ }^{3}$

${ }^{2}$ Department of Epidemiology, Biostatistics and Occupational Health, McGill University, Canada

${ }^{3}$ Injury Epidemiology and Prevention Research Group, Turku Brain Injury Center, University of Turku, Finland

${ }^{4}$ Heidelberg Institute of Global Health, University of Heidelberg, Heidelberg, Germany

Address for correspondence: Michael Lowry Wilson

Heidelberg Institute of Global Health, University of Heidelberg, Heidelberg, Germany

E-mail: michael.1.wilson@utu.fi

\section{ACKNOWLEDGEMENTS}

The authors would like to thank the Namibian Ministry of Health \& Social Services, the Wold Health Organization (Geneva, Switzerland), and the Centers for Disease Control and Prevention (Atlanta, GA). The authors would also like to thank all participating survey officers, teachers, school officials and especially the students that took part in the study. 


\section{ABSTRACT}

Background: Physical fighting is particularly detrimental for young people, often affecting other areas of their developing lives, such as relationships with friends and family and participating in risky behaviors. We aim to quantify the amount of physical fighting in Namibian adolescents and identify modifiable risk factors for intervention.

Methods: We used the Namibia 2013 Global School-based Student Health Survey (GSHS). This survey collects health-related information on school-attending adolescents in grades 7 to 12 . We defined physical fighting as having participated in at least two physical fights in the 12 months prior to responding to the survey. Factors that may be associated with physical fighting were identified a prior based on the literature and included age, sex, anxiety, suicide planning, truancy, physical activity, bullying victimization, presence of supportive parental figures, presence of helpful peers, extent of social network, and food insecurity. Multivariable logistic regression models were created to identify factors associated with physical fighting.

Results: 4,510 adolescents were included in the study. $52.7 \%$ female. $16.9 \%$ of adolescents reported engaging in at least two physical fights in the previous year. Factors associated with an increased odds of physical fighting included having a suicide plan, anxiety, truancy, food deprivation and being bullied. Increased age and loneliness were associated with a decreased odds of physical fighting. 
55 Conclusion: This study identifies physical fighting among adolescents in Namibia. We 56 recommend public health and school-based programming that simultaneously targets risk 57 behaviours and conflict resolution to reduce rates of physical fighting.

58

59 Keywords: Adolescence, physical fighting, sub-saharan Africa

60

61 
63

64

\section{INTRODUCTION}

3

Physical fighting is consistently associated with serious injury and among adolescents is particularly problematic as it is strongly associated with both bullying (perpetration and victimization), family violence and weakened academic achievement (Pickett et al., 2002, 2005). Additionally, individuals who experience physical fighting in adolescence often experience substance use, poor relationships with peers and decreased overall life satisfaction, that extend well into adult life (Krug et al., 2002; Rudatsikira, Muula \& Siziya, 2008a; Patton et al., 2009; Sousa et al., 2010).

Several risk factors for physical fighting have been identified in adolescents, such as male sex, poor mental health, drug use, bullying and younger age (Alikasifoglu et al., 2004; Rudatsikira, Muula \& Siziya, 2008a; Pickett et al., 2012). However, these studies mainly take place in high income countries and quality information regarding the prevalence and general risk factors for physical fighting is lacking in low-income and sub-Saharan African countries. Detailed contextual information on physical fighting risk factors is essential in order to better target adolescents in subSaharan African countries who may at particular risk of participating in physical fighting.

In $2004,51 \%$ of adolescents in Namibia reported having been in at least one physical fight that year (Rudatsikira et al., 2007b). We aim to provide an updated overview of the prevalence and risk factors for physical fighting among adolescents in Namibia using the Namibia Global School-

based Health Survey (GSHS) conducted in 2013. The current study builds upon a previously published study by Rudatsikira et al., where we aim to examine a more contemporary cohort of 
85 Namibian adolescents who exhibit physical fighting behavior and include additional risk factors

86 not previously included in the Rudatsikira et al. study (Rudatsikira et al., 2007b).

87

88 METHODS

89

90

Setting

91

Namibia is a sub-Saharan African country on the south Atlantic coast. It borders Angola, Zambia,

Botswana, and South Africa. It is the driest country in sub-Saharan Africa and has a population of 2.48 million people, with a stable parliamentary democracy. In 2018 . approximately $37 \%$ of its population was under the age of 14 years (World Bank, 2019). Although increasing, Namibia's Human Development Index is low at 0.640 positioning it at $125 / 188$ countries, next to Guatemala 96 (UNDP, 2016).

\section{Sample}

We used the publicly available data from Namibia for the Global School-based Student Health

Survey (GSHS), 2013 (CDC, 2013). The World Health Organization in collaboration with United

States Centers for Disease Control developed the methodology for the GSHS. Detailed information on the data collection methods, questionnaire, and procedures may be found elsewhere (http://www.cdc.gov/gshs/). The survey was administered to school attending adolescents and collected self-reported information on indices pertaining to health risk behaviors. In Namibia, 4,531 students in grades 7 to 12 and aged $13-17$ (52.7\% female) completed the survey questionnaire; with a $100 \%$ school response rate, and an $89 \%$ student response rate. We did not exclude any cases, despite 61 records missing sex and 45 records missing age (with 10 records missing both) information; to ensure correct design-based analysis. 


\section{Measurements}

111 The dependent variable, physical fighting, was derived from one question in the GSHS: “During

112 the past 12 months, how many times were you in a physical fight?" Response options ranged from "0 times", "1 time”, "2 or 3 times", "4 or 5 times", "6 or 7 times", "8 or 9 times”, "10 or 11

114 times" or "12 or more times". For the purpose of our analyses, participants were classified as

115 having participated in a physical fight if they reported being in two or more fights. If none or one

116 fight was reported, participants were classified as not participating in a physical fight. For 21

117 records, this information was missing.

119 We investigated eleven independent variables at the individual level (age, sex, anxiety, suicide planning, truancy, physical activity, bullying victimization, early sexual debut, alcohol use, marijuana use, and cigarette smoking) and four independent variables at the social level (presence of supportive parental figures, presence of helpful peers, extent of social network, and food insecurity). Details on how these variables were created are provided in Table 1.

\section{Statistical analysis}

126 The distribution of selected independent variables within the dichotomized physical fighting 127 variable was examined first. Differences between physical fighting involvement among the variables were screened for statistical significance using Rao-Scott chi-square tests for categorical variables and the design-adjusted version of t-test for continuous variables (age). We then created two sets of survey binary logistic regression models. These were intended to model the ability of

131 the selected independent variables to predict the dichotomized physical fighting variable. The first 
132 set of models included only the predictor variable and adjusted for age and sex. The second model 133 included all variables which were significant at a p-value of 0.05 at the bivariate level. We reported 134 the measures of association as adjusted (aOR) and unadjusted (OR) odds ratios and associated 95\% 135 confidence intervals (CI). All analyses were carried out using Stata 15 (StataCorp, 2017). All 136 proportions - expressed in percentages - are weighted, unless specified otherwise.

137 


\section{RESULTS}

139

4,531 students in grades 7 to 12 aged 13 to 17 (52.7\% female) completed the survey questionnaire.

141 Twenty-one students were excluded with missing 'physical fights' information, resulting in a final sample size of 4,510 adolescents. For comparison purposes we measured 1 or more and 2 more physical fights in the past year, but use 2 or more physical fights as the main outcome throughout

144 the study. Within the recall period, 32.5\% (unweighted count: 1,493) of participants reported being involved in 1 or more physical fights and 16.9\% (unweighted count: 785) of participants reported being involved in two or more physical fights in the past year, most of whom were male (59.7\%). Parents or guardians understanding of respondent's problems and worries was reported as either never, rarely, or sometimes by $59.6 \%$. Having made a plan about how one would attempt suicide was reported by $25.5 \%$. Regarding use of addictive substances and having sex; $21.0 \%$ reported early sexual debut, defined as having had sex before turning 15 years old. Alcohol use, marijuana use and smoking cigarette for one or more days, during the past 30 days was reported by $33.6 \%$, $5.3 \%$, and $9.6 \%$ respectively.

Table 2 provides the weighted distribution of selected factors according to physical fighting category. In the bivariate analyses, eleven out of the seventeen variables were statistically significantly associated with participants who had been involved in two or more physical fights.

157 The age and sex adjusted analyses (Table 3) for all the variables found to be statistically significant 158 in bivariate analysis, revealed statistically significant associations for all selected variables. 
160 Table 4 provides results of adjusted analysis for all covariates in the model. Compared to those 161 who did not report being involved in physical fighting, those who had been involved in physical

162 fights were males (OR 2.06; CI 1.54-2.76), more likely to have made suicide plan (OR 2.10; CI 163 1.66-2.65), were truant (OR 1.60; CI 1.08-2.38), food deprived (OR 1.90; CI 1.41-2.57), having 164 been bullied (OR 2.35; CI 1.79-3.09), had early sexual debut (OR 1.43; CI 1.20-1.71), and were 165 cigarette smokers (OR 1.99; CI 1.19-3.32). While age bestowed protection against involvement in 166 physical fighting (OR 0.89; CI 0.84-0.94). Anxiety, alcohol use, and marijuana users were not 167 found to be statistically significantly associated with physical fighting. The goodness-of-fit test 168 revealed that this was a good multivariable logistic model for physical fight in Namibian students 169 (F: 0.93, p-value: 0.5264). With the exception of having been truant and smoked cigarettes, all 170 other covariates that were statistically significant at p-value of less than 0.05 .

\section{DISCUSSION}

173

174 This study described the prevalence and factors associated with physical fighting among school175 attending adolescents residing in Namibia. We found the prevalence of participating in at least two 176 physical fights among school attending adolescents in Namibia was almost 17\%. Factors 177 associated with an increased odds of physical fighting included having a suicide plan, anxiety, 178 truancy, food deprivation, being bullied, early sexual debut and cigarette smoking. Increased age 179 was associated with a decreased odds of physical fighting.

181 Namibia was found to have a relatively low prevalence of physical fighting, especially compared 182 to other sub-Saharan African countries, and even slightly lower when compared to some high- 
183 income countries (Pickett et al., 2012). For example, a similar survey in Canada found that 19.3\%

184 of adolescents participated in two or more fights (Djerboua, Chen \& Davison, 2016). Interestingly,

185 relative to other sub-Saharan African countries, rates of physical fighting appear to be particularly

186 low in Namibia (Rudatsikira et al., 2007b; Acquah et al., 2014a). For reference, in Ghana,

187 approximately $32 \%$ of adolescents participated in two or more physical fights in the year prior to

188 the survey (Acquah et al., 2014a,b). A similar study in Namibia found that 50\% of adolescents

189 had been in one physical fight in the last 12 months from the time of the survey, compared to the

190 present study which found only 32.5\% (Rudatsikira et al., 2007b). This may reflect an

191 improvement in physical fighting between 2007 and 2013, or differences in respondent

192 characteristics between the years.

193

194 Cultural or educational differences in Namibia may result in lower rates of physical fighting when

195 compared to other sub-Saharan African countries. Although the human development index in

196 Namibia is low, and poverty as well as income disparity have been shown to be associated with

197 increased physical fighting, there may be other positive influences that discourage physical

198 fighting among adolescents in the country. For instance, school environment has been shown in

association with physical fighting among school-aged children (Larsen, 2003; Limbos \& Casteel,

200 2008). Namibia has free education and spent 9.2\% of GDP on education in 2014, perhaps

201 indicating a positive school environment that may mitigate physical fighting in the country

202 (Ministry of Education, Arts and Culture, 2017).

203

204 We found several factors associated with physical fighting. Physical fighting is predominantly

205 present in young adolescent males; Sex and age have both been established as common risk factors 
206 for physical fighting (Pickett et al., 2005, 2012). In line with previous literature in low-income

207 countries, we identified the following factors in association with increased physical fighting:

208 having a suicide plan, anxiety, truancy, food deprivation, being bullied, early sexual debut and

209 cigarette smoking (Rudatsikira, Muula \& Siziya, 2008b; Rudatsikira et al., 2008; Celedonia et al.,

210 2013). Previous studies have demonstrated clustering of risky behaviors, such as truancy, cigarette

211 smoking and alcohol abuse, which may explain the association of physical fighting with suicide

212 planning and truancy (Petridou et al., 1997; Pickett et al., 2002; Acquah et al., 2014a; Yang et al.,

213 2017). Being bullied has been previously shown in association with violence and physical fighting,

214 indicating that those individuals who are victimized are more likely to perpetuate that violence

215 elsewhere (Rudatsikira et al., 2007a; Pickett et al., 2012). This may also be associated with factors

216 of low income, such as food deprivation. Lower socioeconomic status and income disparities have

217 been found in association with physical fighting in other studies (Pickett et al., 2012).

218

219 Interestingly, none of the factors we hypothesized to have a positive influence on adolescents, such

220 as supportive parents, positive peers, physical activity and close friends, were significantly

221 associated with physical fighting on descriptive analyses, although having supportive parents was

222 close $(p$-value $=0.06)$. In this study, loneliness was associated with decreased odds of physical

223 fighting. One hypothesis may be that adolescents with a smaller social circle are less likely to

224 engage in delinquent behavior such as physical fighting (Haynie, 2002).

225

226 Although we found relatively low rates of physical fighting in Namibia, this number is still high

227 at almost $17 \%$ of adolescents participating in at least two fights and represents an area for

228 intervention. By identifying factors associated with physical fighting policy makers are able to 
229 better target populations who may be at particular risk of participating in this risky behavior, such

230 as younger adolescent males and those who may be dealing with other social issues, such as

231 anxiety, suicidal thoughts and bullying. School programming has shown success in reducing

232 physical fighting among school-aged youth and those programs that specifically target high risk

233 youth are particularly successful (Wilson, Lipsey \& Derzon, 2003; Espelage et al., 2013).

235 This study has several limitations. First, the cross-sectional nature of the survey means that we cannot make any reference to causation, only association. However, this still allows us to identify potential groups at higher risk for physical fighting. Second, the survey does not capture students who were not present on the day of the survey or those students who do not attend school for other reasons. These students may be part of vulnerable populations, such as low-income groups, and may be more likely to express risky behavior, thus potentially underestimating the risk of physical fighting. Third, the survey is self-report which, although anonymous, may result in social desirability response bias, which would bias our results towards the null. Fourth, we were limited to the variables collected by the survey and therefore may be missing important protective factors that may be associated with physical fighting, such as the potential protective effects of family life in community activities(Fontaine et al., 2016; Ttofi et al., 2016; Vassallo, Edwards \& Forrest,

247 2016). Finally, we used a robust definition of two or more physical fights in the last year to capture more repetitive behavior, however, this definition makes comparisons to other classifications more difficult. We believe that the associations between risk factors and physical fighting would not change significantly between these definitions, except in strength of association. Despite these 
251 limitations, this study provides information on physical fighting in a large updated and

252 representative sample of all school-attending adolescents aged 11-16 in Namibia.

253

254 CONCLUSION

255

256 This study provides an updated description of physical fighting in Namibia as well as factors that 257 can be used to identify populations for intervention programs. Although physical fighting was 258 found to be relatively low in Namibia compared to other sub-Saharan countries, it is still a 259 modifiable risky behavior that can be altered in this young population. We recommend public 260 health and school-based programming that simultaneously targets risk behaviors and conflict 261 resolution to reduce rates of physical fighting. Future iterations of the survey would benefit from 262 the inclusion of more family and peer-related factors which may help to identify additional 263 correlates that may mitigate aggressive behaviors.

264

ACKNOWLEDGEMENTS

Author M.L.W. was supported by the Alexander von Humboldt-Stiftung, Bonn, Germany.

Author AA was supported by the EDCTP/TDR Clinical Research and Development

Fellowship Program, World Health Organization, Geneva, Switzerland; a grant from The

John Harvey Lowery Foundation, USA; and the University of Turku Joint Research Grant 
271

272

273

274

275

276

277

278

279

280

281

282

283

284

285

286

287

288

289

290

291

292

293

\section{REFERENCES}

Acquah E, Lloyd J, Davis L, Wilson M, Acquah EO, Lloyd JK, Davis L, Wilson ML. 2014a. Adolescent Physical Fighting in Ghana, Their Demographic and Social Characteristics. Social Sciences 3:227-241. DOI: 10.3390/socsci3020227.

Acquah E, Wilson M, Doku D, Acquah EO, Wilson ML, Doku DT. 2014b. Patterns and Correlates for Bullying among Young Adolescents in Ghana. Social Sciences 3:827-840. DOI: $10.3390 /$ socsci3040827.

Alikasifoglu M, Erginoz E, Ercan O, Uysal O, Kaymak DA, Ilter O. 2004. Violent behaviour among Turkish high school students and correlates of physical fighting. European Journal of Public Health 14:173-177. DOI: 10.1093/eurpub/14.2.173.

CDC. 2013.Namibia - Global School-based Student Health Survey (GSHS). Available at https://www.cdc.gov/gshs/countries/africa/namibia.htm (accessed November 17, 2018).

Celedonia KL, Wilson ML, Gammal HAE, Hagras AM. 2013. Physical fighting among Egyptian adolescents: social and demographic correlates among a nationally representative sample. PeerJ 1:e125. DOI: 10.7717/peerj.125.

Djerboua M, Chen BE, Davison C. 2016. Trends and demographic characteristics of physical fighting and fighting-related injuries among Canadian youth, 1993-2010. Can J Public Health 107:231-238. DOI: 10.17269/cjph.107.5274.

Espelage DL, Low S, Polanin JR, Brown EC. 2013. The Impact of a Middle School Program to Reduce Aggression, Victimization, and Sexual Violence. Journal of Adolescent Health 53:180-186. DOI: 10.1016/j.jadohealth.2013.02.021.

Fontaine NMG, Brendgen M, Vitaro F, Tremblay \& RE. 2016. Compensatory and protective factors against violent delinquency in late adolescence: Results from the Montreal 
longitudinal and experimental study. Journal of Criminal Justice 45:54-62. DOI: 10.1016/j.jcrimjus.2016.02.013.

296

297

298

299

300

301

302

303

304

305

306

307

Haynie DL. 2002. Friendship Networks and Delinquency: The Relative Nature of Peer Delinquency. Journal of Quantitative Criminology 18:99-134. DOI: 10.1023/A:1015227414929.

Krug EG, Mercy JA, Dahlberg LL, Zwi AB. 2002. The world report on violence and health. The Lancet 360:1083-1088. DOI: 10.1016/S0140-6736(02)11133-0.

Larsen E. 2003. Violence in U.S. Public Schools: A Summary of Findings. ERIC Digest. ERIC Clearinghouse on Urban Education, Institute for Urban and Minority Education, Box 40, Teachers College, Columbia University, New York, NY 10027.

Limbos MAP, Casteel C. 2008. Schools and Neighborhoods: Organizational and Environmental Factors Associated With Crime in Secondary Schools*. Journal of School Health 78:539-544. DOI: 10.1111/j.1746-1561.2008.00341.x.

Ministry of Education, Arts and Culture. 2017. A public expenditure review of the basic education sector in Namibia. Republic of Namibia: UNICEF.

Patton GC, Coffey C, Sawyer SM, Viner RM, Haller DM, Bose K, Vos T, Ferguson J, Mathers CD. 2009. Global patterns of mortality in young people: a systematic analysis of population health data. The Lancet 374:881-892. DOI: 10.1016/S0140-6736(09)60741-8.

Petridou E, Zavitsanos X, Dessypris N, Frangakis C, Mandyla M, Doxiadis S, Trichopoulos D. 1997. Adolescents in High-Risk Trajectory: Clustering of Risky Behavior and the Origins of Socioeconomic Health Differentials. Preventive Medicine 26:215-219. DOI: 10.1006/pmed.1996.0130. 
316 Pickett W, Craig W, Harel Y, Cunningham J, Simpson K, Molcho M, Mazur J, Dostaler S, 317 Overpeck MD, Currie CE. 2005. Cross-national Study of Fighting and Weapon Carrying

Pickett W, Molcho M, Elgar FJ, Brooks F, Looze M de, Rathmann K, Bogt TFM ter, Gabhainn

Rudatsikira E, Mataya RH, Siziya S, Muula AS. 2008. Association between bullying victimization and physical fighting among Filipino adolescents: Results from the Global School-Based Health Survey. The Indian Journal of Pediatrics 75:1243-1247. DOI: 10.1007/s12098-008-0244-x.

Rudatsikira E, Muula AS, Siziya S. 2008a. Variables associated with physical fighting among US high-school students. Clinical Practice and Epidemiology in Mental Health 4:16. DOI: $10.1186 / 1745-0179-4-16$.

Rudatsikira E, Muula AS, Siziya S. 2008b. Prevalence and correlates of physical fighting among school-going adolescents in Santiago, Chile. Brazilian Journal of Psychiatry 30:197-202. DOI: $10.1590 / \mathrm{S} 1516-44462008000300004$. 
338 Rudatsikira E, Singh P, Job J, Knutsen S. 2007a. Variables Associated with Weapon-Carrying

339 among Young Adolescents in Southern California. Journal of Adolescent Health 40:470 473. DOI: 10.1016/j.jadohealth.2006.12.011.

341 Rudatsikira E, Siziya S, Kazembe LN, Muula AS. 2007b. Prevalence and associated factors of physical fighting among school-going adolescents in Namibia. Annals of General Psychiatry 6:18. DOI: 10.1186/1744-859X-6-18.

344

Sousa S, Correia T, Ramos E, Fraga S, Barros H. 2010. Violence in adolescents: social and behavioural factors. Gaceta Sanitaria 24:47-52. DOI: 10.1016/j.gaceta.2009.08.002.

Ttofi MM, Farrington DP, Piquero AR, DeLisi M. 2016. Protective factors against offending and violence: Results from prospective longitudinal studies. Journal of Criminal Justice 45:1-3. DOI: 10.1016/j.jcrimjus.2016.02.001.

UNDP. 2016.Human Development Report 2016 - Human Development for Everyone. Available at http://www.in.undp.org/content/india/en/home/library/hdr/human-developmentproducts/human-development-report-2016---human-development-for-everyone.html (accessed September 25, 2018).

Vassallo S, Edwards B, Forrest W. 2016. Childhood behavior problems and fighting in early adulthood: What factors are protective? Journal of Criminal Justice 45:85-93. DOI: 10.1016/j.jcrimjus.2016.02.010.

Wilson SJ, Lipsey MW, Derzon JH. 2003. The effects of school-based intervention programs on aggressive behavior: a meta-analysis. Journal of Consulting and Clinical Psychology $71: 136-149$.

World Bank. 2019. United Nations Population Division's World Population Prospects: 2019 Revision. Population ages 0-14 (\% of total population). Washington DC: World Bank. 
361 Yang L, Zhang Y, Xi B, Bovet P, Yang L, Zhang Y, Xi B, Bovet P. 2017. Physical Fighting and Associated Factors among Adolescents Aged 13-15 Years in Six Western Pacific DOI: 10.3390/ijerph14111427.

365

366 
Table $\mathbf{1}$ (on next page)

Table 1 
1 Table 1: Independent variable derivation from GSHS survey data 2013.

2

\begin{tabular}{|c|c|c|}
\hline Survey question & Coding & Variable \\
\hline \multicolumn{3}{|l|}{ Individual-level variables } \\
\hline How old are you? & $11-18$ years (coded continuous) & Age \\
\hline \multirow[t]{2}{*}{ What is your sex? } & Female $(0)$ & Sex \\
\hline & Male (1) & \\
\hline $\begin{array}{l}\text { During the past } 12 \text { months, how often have you been } \\
\text { so worried about something that you could not sleep } \\
\text { at night? }\end{array}$ & $\begin{array}{l}\text { Most of the time/always (1) } \\
\text { Never/rarely/sometimes (0) }\end{array}$ & Anxiety \\
\hline $\begin{array}{l}\text { During the past } 12 \text { months, did you make a plan } \\
\text { about how you would attempt suicide? }\end{array}$ & $\begin{array}{l}\text { No (0) } \\
\text { Yes (1) }\end{array}$ & Suicide Plan \\
\hline $\begin{array}{l}\text { During the past } 12 \text { months, how often have you felt } \\
\text { lonely? }\end{array}$ & $\begin{array}{l}\text { Never/rarely/sometimes (0) } \\
\text { Most of the time/always (1) }\end{array}$ & Loneliness \\
\hline $\begin{array}{l}\text { During the past } 30 \text { days, how many days did you } \\
\text { miss classes or school without permission? }\end{array}$ & $\begin{array}{l}0-2 \text { times }(0) \\
3 \text { to or more days }(1)\end{array}$ & Truancy \\
\hline $\begin{array}{l}\text { During the past } 30 \text { days, on how many days were } \\
\text { you bullied? }\end{array}$ & $\begin{array}{l}0 \text { times }(0) \\
1 \text { or more times }(1)\end{array}$ & Bullying victimization \\
\hline $\begin{array}{l}\text { During the past } 7 \text { days, on how many days were you } \\
\text { physically active for a total of at least } 60 \text { min per } \\
\text { day? }\end{array}$ & $\begin{array}{l}3 \text { days or less }(0) \\
4 \text { days or more }(1)\end{array}$ & Physical activity \\
\hline $\begin{array}{l}\text { How much time do you spend during a typical or } \\
\text { usual day sitting and watching television, playing } \\
\text { computer games, talking with friends, or doing other } \\
\text { sitting activities? }\end{array}$ & $\begin{array}{l}2 \mathrm{~h} \text { or less }(0) \\
3 \mathrm{~h} \text { or more }(1)\end{array}$ & Sedentary \\
\hline $\begin{array}{l}\text { How old were you when you had sexual intercourse } \\
\text { for the first time? }\end{array}$ & $\begin{array}{l}\text { Never had sex or had after age } \\
14(0) \\
\text { Had sex at age } 14 \text { or earlier (1) }\end{array}$ & Early sexual debut \\
\hline
\end{tabular}




\begin{tabular}{|c|c|c|}
\hline $\begin{array}{l}\text { During the past } 30 \text { days, on how many days did you } \\
\text { have at least one drink containing alcohol? }\end{array}$ & $\begin{array}{l}0 \text { days }(0) \\
1 \text { or more days }(1)\end{array}$ & Alcohol use \\
\hline $\begin{array}{l}\text { During the past } 30 \text { days, how many times have you } \\
\text { used marijuana (also called dagga, weed, boom, } \\
\text { cannibus, stop, grass, pipt, stop, and joint)? }\end{array}$ & $\begin{array}{l}0 \text { days }(0) \\
1 \text { or more days }(1)\end{array}$ & Marijuana use \\
\hline $\begin{array}{l}\text { During the past } 30 \text { days, on how many days did you } \\
\text { smoke cigarettes? }\end{array}$ & $\begin{array}{l}0 \text { days }(0) \\
1 \text { or more days }(1)\end{array}$ & Cigarette smoking \\
\hline \multicolumn{3}{|l|}{ Social-level variables } \\
\hline $\begin{array}{l}\text { During the past } 30 \text { days, how often did your parents } \\
\text { or guardians understand your problems and worries? }\end{array}$ & $\begin{array}{l}\text { Never/rarely/sometimes (0) } \\
\text { Most of the time/always (1) }\end{array}$ & $\begin{array}{l}\text { Supportive parental } \\
\text { figures }\end{array}$ \\
\hline $\begin{array}{l}\text { During the past } 30 \text { days, how often were most of the } \\
\text { students in your school kind and helpful? }\end{array}$ & $\begin{array}{l}\text { Never/rarely/sometimes (0) } \\
\text { Most of the time/Always (1) }\end{array}$ & Helpful peers \\
\hline How many close friends do you have? & $\begin{array}{l}0 \text { close friends (0) } \\
1 \text { close friends (1) } \\
2 \text { close friends (2) } \\
3+\text { close friends ( } 3 \text { ) } \\
\text { (coded continuous) }\end{array}$ & Close friends \\
\hline $\begin{array}{l}\text { During the past } 30 \text { days, how often did you go } \\
\text { hungry because there was not enough food in your } \\
\text { home? }\end{array}$ & $\begin{array}{l}\text { Never/rarely/sometimes (0) } \\
\text { Most of the time/always (1) }\end{array}$ & Food insecurity \\
\hline
\end{tabular}

3

4

5

6 
Table 2 (on next page)

Table 2 
1 Table 2: Distribution of selected factors according to categories of physical fighting among school-

2 attending adolescents in Namibia, GSHS 2013

\begin{tabular}{|l|l|l|l|}
\hline Variable & $\begin{array}{l}\text { Not involved in }<\mathbf{2} \\
\text { physical fights } \\
(\mathbf{n = 3 , 7 2 5 )}\end{array}$ & $\begin{array}{l}\text { Involved in } \geq \mathbf{2} \\
\text { physical fights } \\
\mathbf{( n = 7 8 5 )}\end{array}$ & P-value* \\
\hline Age (SD) & $15.9(1.8)$ & $15.7(1.8)$ & 0.009 \\
\hline Sex (male) & 44.3 & 59.7 & $<0.001$ \\
\hline Anxiety & 13.9 & 22.5 & $<0.001$ \\
\hline Loneliness & 15.1 & 16.7 & 0.041 \\
\hline Food deprivation & 8.2 & 17.9 & $<0.001$ \\
\hline Close friends (SD) & $1.9(1.1)$ & $1.9(1.1)$ & 0.54 \\
\hline Bullying victimization & 40 & 67.3 & $<0.001$ \\
\hline Truancy & 8.1 & 19.2 & $<0.001$ \\
\hline Physical Activity & 26.4 & 28.7 & 0.134 \\
\hline Sedentary & 35.1 & 40.5 & 0.087 \\
\hline Supportive parental figures & 41.1 & 36.7 & 0.062 \\
\hline Helpful peers & 13.4 & 14 & 0.688 \\
\hline Suicide planning & 22.3 & 41.1 & $<0.001$ \\
\hline Early sexual debut & 18.8 & 32.8 & $<0.001$ \\
\hline Alcohol use & 32.6 & 38.8 & 0.002 \\
\hline Marijuana use & 3.7 & 13.0 & $<0.001$ \\
\hline Cigarette smoking & 7.2 & 21.1 & $<0.001$ \\
\hline
\end{tabular}

3 All variables are expressed as proportions (in \%) with the exception of age and close friends (mean and standard deviation).

$4 *$ Chi-square test for significance. 
Table 3 (on next page)

Table 3 
1 Table 3: Multivariate analysis identifying correlates of physical fighting among school-attending 2 adolescents in Namibia, GSHS 2013.

\begin{tabular}{|l|l|l|l|}
\hline Main risk factor & OR & $\mathbf{9 5 \%}$ CI & $\boldsymbol{p}$-value \\
\hline Age (SD) & 0.91 & $0.86-0.96$ & 0.001 \\
\hline Sex (male) & 1.94 & $1.55-2.42$ & $<0.001$ \\
\hline Anxiety & 1.93 & $1.53-2.45$ & $<0.001$ \\
\hline Food deprivation & 2.45 & $1.81-3.33$ & $<0.001$ \\
\hline Bullying victimization & 3.16 & $2.49-4.00$ & $<0.001$ \\
\hline Truancy & 2.82 & $1.94-4.09$ & $<0.001$ \\
\hline Suicide planning & 2.55 & $2.19-2.96$ & $<0.001$ \\
\hline Early sexual debut & 1.74 & $1.44-2.10$ & $<0.001$ \\
\hline Alcohol use & 1.34 & $1.13-1.59$ & 0.001 \\
\hline Marijuana use & 3.62 & $2.31-5.68$ & $<0.001$ \\
\hline Cigarette smoking & 3.14 & $2.38-4.14$ & $<0.001$ \\
\hline
\end{tabular}

3 Abbreviations: OR, Odds Ratio; 95\% CI, 95\% Confidence Interval.

4 All estimates are adjusted for age and sex; age; or sex.

5

6

7

8

9

10

11 
Table 4 (on next page)

Table 4 
1 Table 4: Outcomes of multivariate analysis of variables associated with two or more physical fighting

2 episodes among school-attending adolescents in Namibia, GSHS 2013

\begin{tabular}{|l|l|l|l|}
\hline Variable & Adjusted OR & $\mathbf{9 5} \%$ CI & P-value \\
\hline Age & 0.89 & $0.84-0.94$ & $<0.001$ \\
\hline Sex & 2.06 & $1.54-2.76$ & $<0.001$ \\
\hline Anxiety & 1.37 & $0.97-1.92$ & 0.071 \\
\hline Food deprivation & 1.90 & $1.41-2.57$ & $<0.001$ \\
\hline Bullying victimization & 2.35 & $1.79-3.09$ & $<0.001$ \\
\hline Truancy & 1.60 & $1.08-2.38$ & 0.002 \\
\hline Suicide planning & 2.10 & $1.66-2.65$ & $<0.001$ \\
\hline Early sexual debut & 1.43 & $1.20-1.71$ & $<0.001$ \\
\hline Alcohol use & 0.96 & $0.75-1.22$ & 0.715 \\
\hline Marijuana use & 1.38 & $0.81-2.35$ & 0.219 \\
\hline Cigarette smoking & 1.99 & $1.19-3.32$ & 0.011 \\
\hline
\end{tabular}

3 Only those factors found statistically significant in bivariate analysis were used in this model

4 Abbreviations: CI, Confidence Interval.

5 All estimates are adjusted for all variables listed in the table.

6 